\title{
Evaluation of Forest Products Trade Economic Contribution by Entropy-TOPSIS: Case Study of Turkey
}

\author{
Bahadır Çağrı Bayram
}

The forest products industry is one of the most powerful industry branches of Turkey, and as in other developing countries, Turkey has a persistent trade deficit. The present paper aims to evaluate the forest industry products of Turkey regarding their economic contribution by EntropyTOPSIS, which is a hybrid multicriteria decision making method. The evaluation was done to specify the products which will be able to create currency inflow most for reducing the trade deficit and help economic development. According to computations, the most contributing products are medium-density fiberboard (MDF), high-density fiberboard (HDF), industrial roundwood, and particle board. In addition, household and sanitary papers, as well as other paper and paper board products were found to have great economic potential.

Keywords: Forest products; Turkey; Decision making; Entropy; TOPSIS; Economics

Contact information: Department of Forest Industry Engineering, Kastamonu University, P.O. Box 37100, Kastamonu, Turkey; *Corresponding author: bcbayram@kastamonu.edu.tr

\section{INTRODUCTION}

Recently, the importance of natural resources has increased with the expanding human population, industrialization, consumer demand, and global economic crises. The economic crisis generates heavy pressure on natural resources, and forests are severely affected by this adversity (GDF 2015). In the management process of natural resources, it is necessary to count the consumptive needs of society. Therefore, today many natural resource managers continue to manage wood production in the interest of both nature and humanity (Bettinger et al. 2017). Quantitative methods are typically used to justify or support decisions. Such techniques include economic, biometric, and operation research analysis tools. For considering multiple objects and constraints simultaneously, decision support systems should be used to assist in developing plans (Bettinger et al. 2017).

In the Turkish manufacturing system, the forest products industry is one of the areas where advanced technology and business management practices are applied behind other industries such as the automotive and chemical industry. It is one of the driving industries of the Turkish economy. According to Istanbul Chamber of Industry's (ISO) Turkey's Top 500 Industrial Enterprises 2018 study, which mirrors the industrialization and development process of Turkey (ISO, 2019), 5.8\% (29) of total enterprises are forest product enterprises.

As in other developing countries, trade deficit remains a major problem within the Turkish economy (Kayhan et al. 2013). This trade deficit has been present within the Turkish economy since the liberalization period in the early 1980s (Karagöz 2016). The trade deficit is the gap between a country's exports and imports. It occurs when a country's imports exceed its exports. Overcoming such a gap is possible for developing countries through promoting export revenue (Günçavdı and Suna Kayam 2017).

Today, trade in the world continues to increase rapidly. In 2018, China took first 
place in exports, followed by The United States of America, Germany, Japan, and The Netherlands across all industries. Turkey ranks thirty-first in the world exports with 167.9 billion dollars (Trade Statistics for International Business Development 2019).

Referring to the trade of wood-based products (Product 44) in 2018, China took first place with 14.8 billion dollars, while Turkey ranked thirty-sixth with 826.6 million dollars and $0.6 \%$ of the world's share in exports. Turkey's imports represent $0.5 \%$ of world imports for these products, and its ranking in world imports is thirty-two with 827.9 million dollars (Trade Statistics for International Business Development 2019). Referring to the trade of pulp, recovered paper and paperboard products (Product 47) in 2018, The United States of America took first place with 9.4 billion dollars while Turkey ranked fortyseventh with 32.5 million dollars and $0.1 \%$ of the world's share in exports. Turkey's imports represent $1.7 \%$ of the world's imports for these products, and its ranking in world imports is twelfth with 1 million dollars (Trade Statistics for International Business Development 2019). Referring to the trade of paper and paperboard products (Product 48) in 2018, Germany took first place with 21.6 billion dollars, while Turkey ranked twenty-third with 1.7 billion dollars and 1\% of the world's share in exports. Turkey's imports represent $1.6 \%$ of the world's imports for these products, and its ranking in world imports is fifteenth with 2.7 million dollars (Trade Statistics for International Business Development 2019).

Based on the data collected by the Trade Statistics for International Business, the forest products industry is one of the driving industries in the Turkish economy. Therefore, with better management plans, it has the potential to help reduce the trade deficit. For this reason, the current economic contribution and export potential of products must be known. However, this is a complex problem for which decision support systems are needed. Hence, ranking the economic contribution of the forest industry products of Turkey was chosen as the research subject of this study.

According to the Food and Agriculture Organization of The United Nations (FAO) Yearbook of Forest Products 2016, the names of individual forest products and product aggregates are listed as follows: industrial roundwood, sawn wood, wood-based panels, fiber furnish, paper and paper board, wood fuel, charcoal, and pellets (FAO 2018). Wood fuel, charcoal, and pellets were not considered in this research because they were out of the scope of industrial production. This paper does not deal with any material used for energy purposes. The data about forest products were taken from the FAO Statistics Division (FAOSTAT) and covers the last decade.

The evaluation of forest products was done with the multi-criteria decision making (MCDM) methods. The MCDM methods were used due to the nature of the problem. The objective in solving a MCDM problem is to obtain the optimal solution that has the highest degree of satisfaction for all relevant evaluation criteria (Ouyang et al. 2014).

There are many MCDM methods; they differ in the complexity of use and the need of introducing additional subjective variables such as weights. Hybrid methods can be applied to various problems (Bakhoum and Brown 2013). In the present study, The Technique for Order Preference by Similarity to Ideal Solution (TOPSIS) and entropy methods were chosen because of their suitability and prevalence in practice, and a hybrid approach was applied.

TOPSIS is basically a relative-proximity based nonparametric MCDM tool. It simultaneously copes with multiple measuring metrics for benchmarking the possible alternatives while avoiding the typical rank-conflicting problem through its relative "proximity to the ideal" function (Wang et al. 2017). It has numerous advantages; it is adequate for the use of raw data information, and there are no strict restrictions on the 
number of indicators, it is practical (Long et al. 2019), it logically represents the rational human choice by considering both the best and worst attributes of the alternatives simultaneously, and the computation and the presentation of the results are simple (Abidin et al. 2016).

However, there are some disadvantages; TOPSIS uses Euclidean Distance calculations, which do not consider the correlation of attributes, and it is difficult to weight the attributes (Velasquez and Hester 2013).

In general, the evaluation process of a MCDM problem is greatly affected by the weights of the evaluation criteria and in such conditions, if the weighting process of an analysis is not performed correctly, then the incorrectly generated weights directly affect the outcome. There are various methods have been proposed for calculating and determining the weights of the evaluation criteria (Ouyang et al. 2014).

Today, the weighting methods can be roughly divided into three: subjective weighting, objective weighting, and combined integration weighting assessment. In the subjective weighting method, the weight of each criterion is compared, assigned, and calculated according to the knowledge and experience or preferences of the decisionmakers (Long et al. 2019). The renowned Analytic Hierarchy Process (AHP) is the bestknown of subjective methods. In the objective weighting method, the weight of each criterion is based on the difference in objective data of each criterion value (Long et al. 2019).

Shannon's Entropy method is one of the objective weighting methods that is purely on the basis of unbiased data and consequently is able to overcome the deficiencies of subjective weighting methods (Wang et al. 2017). It can eliminate man-made disturbances and make results in more accord with facts (Li et al. 2011). Entropy theory is versatile, robust and efficient (Bakhoum and Brown 2013) and has been traditionally applied to determine the weight of each criterion (Yang et al. 2018).

The Entropy-TOPSIS method aims to make a comprehensive evaluation. Most of the existing studies by means of TOPSIS calculate the weights based on the AHP, which adds to the subjectivity of analysis results (Ao et al. 2011). Therefore, the present study adopted the Entropy method to eliminate subjectivity.

In recent years, many studies have adopted the Entropy-TOPSIS hybrid method in various areas such as energy performance benchmarking (Wang et al. 2017), blockchain evaluation (Tang et al. 2019), emergency plan optimization (Long et al. 2019), quality characteristics ranking (Ouyang et al. 2014), sustainable ranking of structural materials (Bakhoum and Brown 2013), competitiveness analysis (Kim 2016), safety evaluation (Li et al. 2011), structured selection of settlement (Tianlin et al. 2019), and rail system operation performance evaluation (Huang et al. 2018).

This study was carried out with the intention to rank the forest products according to their economic contribution. This ranking was done to specify the products which will be able to create the most currency inflow, helping planners in the creation of strategies and plans to reduce the trade deficit, and to be an example for various organizations which have similar goals. A further goal was to indicate that MCDM methods are appropriate for this kind of natural resources related planning.

In complex and crucial industries, the use of a hybrid MCDM method proposed by this paper can guide the decision-making process of professionals and researchers. Furthermore, this work can contribute to the forestry literature from a different aspect which is mostly ignored: the decision-making applications in the forest products industry and economics. 


\section{EXPERIMENTAL}

\section{Material and Methods}

The data from Turkey were taken from FAOSTAT, and this paper covers the period between 2008 to 2017. This period is the most current data over the last decade. Before starting the analyses, the decision matrix was created. There are 18 alternatives and 5 criteria in the matrix. The alternatives were chosen as: plywood (PW), particle board (PB), oriented strand board (OSB), hardboard (HB), medium-density fiberboard and highdensity fiberboard (MDF/HDF), other fiber board (OFB), mechanical wood pulp (MWP), semi-chemical wood pulp (SCWP), chemical wood pulp (CWP), pulp from fibers other than wood (PFFOTW), recovered paper (RP), newsprint (NP), printing and writing papers (PWP), other paper and paper board (OPPB), household and sanitary papers (HSP), wrapping, packing paper, and paper board (WPPP), industrial roundwood (IRW), and sawn wood (SW). The alternatives were decided according to the definition of the FAO Yearbook of Forest Products 2016 (FAO 2018). The criteria were determined as: production quantity, import quantity, import value, export quantity, and export value. The criteria selection is based on data availability. According to the conducted research it was seen that it is difficult to find a reliable data source for this kind of research. The trustworthy and comprehensive data were only found at FAOSTAT. Therefore, the criteria were accepted on the basis of data availability as given in FAOSTAT.

The data of the decision matrix were derived from the last 10 years of each alternative and criterion one by one. The arithmetic mean was used for the quantity related data, while the weighted mean was used for the value-related data. See Table 1 below for the decision matrix.

Table 1. Decision Matrix (FAOSTAT 2019)

\begin{tabular}{|c|c|c|c|c|c|}
\hline & $\begin{array}{c}\text { Production } \\
\left(\mathrm{m}^{3} / \text { tonnes }\right)\end{array}$ & $\begin{array}{c}\text { Import } \\
\text { Quantity } \\
\left(\mathrm{m}^{3} / \text { tonnes }\right)\end{array}$ & $\begin{array}{c}\text { Import Value } \\
(\$ 1000)\end{array}$ & $\begin{array}{c}\text { Export } \\
\text { Quantity } \\
\left(\mathrm{m}^{3} / \text { tonnes }\right)\end{array}$ & $\begin{array}{c}\text { Export Value } \\
(\$ 1000)\end{array}$ \\
\hline PW & 115900 & 241063 & 267761 & 21715 & 16354 \\
\hline PB & 3751500 & 134210 & 37686 & 426782 & 103699 \\
\hline OSB & 56500 & 175690 & 49834 & 3697 & 1589 \\
\hline HB & 30400 & 200985 & 141457 & 60995 & 33758 \\
\hline MDF/HDF & 3933500 & 246179 & 98100 & 526180 & 245934 \\
\hline OFB & 21900 & 2572 & 4014 & 27667 & 15961 \\
\hline MWP & 0 & 4328 & 3754 & 78 & 203 \\
\hline SCWP & 65500 & 4258 & 4688 & 4 & 26 \\
\hline CWP & 0 & 866364 & 608735 & 13233 & 18990 \\
\hline PFFOTW & 53000 & 1692 & 2305 & 178 & 157 \\
\hline RP & 1611700 & 217590 & 78129 & 53087 & 12385 \\
\hline NP & 0 & 412272 & 275944 & 1271 & 1125 \\
\hline PWP & 314848 & 834529 & 850515 & 19485 & 22490 \\
\hline OPPB & 2339856 & 1307029 & 1105543 & 398146 & 430629 \\
\hline HSP & 121008 & 7857 & 14792 & 151389 & 211628 \\
\hline WPPP & 2193336 & 1260337 & 1005886 & 244288 & 219710 \\
\hline IRW & 17368900 & 768759 & 135850 & 7187 & 2042 \\
\hline SW & 6884100 & 936710 & 224453 & 28132 & 12820 \\
\hline
\end{tabular}

In this paper, A hybrid MCDM method (Entropy-TOPSIS) was applied for an objective evaluation. Entropy was used for calculating the attribute weights and TOPSIS 
was used for evaluating the alternatives comprehensively. As a means to obtaining precise results, before starting the TOPSIS analysis, the weights of the criteria were calculated with the entropy method.

In the evaluation field, decision-making models based on statistical data of historical events have been widely used (Long et al. 2019). TOPSIS is one of the wellknown MCDM approaches (Ouyang et al. 2014), which was first developed by Hwang and Yoon in 1981. Today, TOPSIS has been applied as a decision-making tool for different areas (Abidin et al. 2016). TOPSIS is suitable for cases with many attributes and alternatives, as well as being handy for objectives with quantitative data (Sayareh and Alizmini 2014). In TOPSIS, the weights of attributes are of great importance; therefore, it is necessary to develop a weighting algorithm calculation in order to maintain consistency of judgement of the decision-making method (Kim 2016). The entropy method is an objective method to calculate the weight of evaluation factors (Zhou et al. 2016). It is based on Shannon Entropy, originally developed by Shannon in 1948. Entropy is a simple and effective method for determining the weights of evaluation criteria in a MCDM problem (Ouyang et al. 2014). Entropy presents no major modelling difficulties and renders decision making more accurate and reliable (Song et al. 2017).

\section{The Steps of the Entropy Method}

The method involves the following steps:

1) Construct a decision matrix,

2) Normalize the decision matrix,

3) Calculate the entropy value for each evaluation criterion,

4) Compute the weight vector for all evaluation criteria.

The executed calculations are based on the algorithm given in Li et al. (2011), which can be consulted for details.

According to evaluation indexes, which are the benefit indexes or cost indexes, the standardization of the indexes is calculated and shown by the index below:

$R i j=\left[\begin{array}{lllll}0.00298 & 0.00257 & 0.00281 & 0.01095 & 0.01212 \\ 0.09653 & 0.00462 & 0.01994 & 0.21516 & 0.07684 \\ 0.00145 & 0.00353 & 0.01508 & 0.00186 & 0.00118 \\ 0.00078 & 0.00309 & 0.00531 & 0.03075 & 0.02502 \\ 0.10122 & 0.00252 & 0.00766 & 0.26528 & 0.18224 \\ 0.00056 & 0.24109 & 0.18720 & 0.01395 & 0.01183 \\ 0.00000 & 0.14328 & 0.20019 & 0.00004 & 0.00015 \\ 0.00169 & 0.14562 & 0.16029 & 0.00000 & 0.00002 \\ 0.00000 & 0.00072 & 0.00123 & 0.00667 & 0.01407 \\ 0.00136 & 0.36652 & 0.32596 & 0.00009 & 0.00012 \\ 0.04147 & 0.00285 & 0.00962 & 0.02676 & 0.00918 \\ 0.00000 & 0.00150 & 0.00272 & 0.00064 & 0.00083 \\ 0.00810 & 0.00074 & 0.00088 & 0.00982 & 0.01667 \\ 0.06021 & 0.00047 & 0.00068 & 0.20073 & 0.31910 \\ 0.00311 & 0.07892 & 0.05080 & 0.07632 & 0.15682 \\ 0.05644 & 0.00049 & 0.00075 & 0.12316 & 0.16281 \\ 0.44694 & 0.00081 & 0.00553 & 0.00362 & 0.00151 \\ 0.17714 & 0.00066 & 0.00335 & 0.01418 & 0.00950\end{array}\right]$

The weights of the indexes are calculated and shown in Table 2. 
Table 2. Calculated Index Weights

\begin{tabular}{|c|c|c|c|c|c|}
\hline & $\begin{array}{c}\text { Production } \\
\left(\mathrm{m}^{3} / \text { tonnes }\right)\end{array}$ & $\begin{array}{c}\text { Import } \\
\text { Quantity } \\
\left(\mathrm{m}^{3} / \text { tonnes }\right)\end{array}$ & $\begin{array}{c}\text { Import Value } \\
(\$ 1000)\end{array}$ & $\begin{array}{c}\text { Export Quantity } \\
\left(\mathrm{m}^{3} / \text { tonnes }\right)\end{array}$ & $\begin{array}{c}\text { Export Value } \\
(\$ 1000)\end{array}$ \\
\hline $\mathrm{Wj}$ & 0.22 & 0.23 & 0.20 & 0.17 & 0.18 \\
\hline
\end{tabular}

After calculation of the weights, TOPSIS method was used for ranking the alternatives.

\section{The Steps of the TOPSIS Method}

The TOPSIS Method has the following steps:

1) Construct a decision matrix,

2) Normalize the decision matrix,

3) Determine the weighted decision matrix,

4) Determine ideal and negative-ideal solutions,

5) Calculate the distance,

6) Calculate the relative degree of approximation,

7) Ranking

The executed calculations are based on the algorithm given in Ouyang et al. (2014); for details see therein.

According to the data in Table 1, the normalized decision matrix is given below:

$$
R i j=\left[\begin{array}{lllll}
0.00586 & 0.09357 & 0.14143 & 0.02578 & 0.02754 \\
0.18957 & 0.05209 & 0.01990 & 0.50674 & 0.17464 \\
0.00286 & 0.06819 & 0.02632 & 0.00439 & 0.00268 \\
0.00154 & 0.07801 & 0.07472 & 0.07242 & 0.05685 \\
0.19876 & 0.09555 & 0.05181 & 0.62476 & 0.41417 \\
0.00111 & 0.00100 & 0.00212 & 0.03285 & 0.02688 \\
0.00000 & 0.00168 & 0.00198 & 0.00009 & 0.00034 \\
0.00331 & 0.00165 & 0.00248 & 0.00000 & 0.00004 \\
0.00000 & 0.33627 & 0.32152 & 0.01571 & 0.03198 \\
0.00268 & 0.00066 & 0.00122 & 0.00021 & 0.00026 \\
0.08144 & 0.08446 & 0.04127 & 0.06303 & 0.02086 \\
0.00000 & 0.16002 & 0.14575 & 0.00151 & 0.00190 \\
0.01591 & 0.32392 & 0.44923 & 0.02314 & 0.03788 \\
0.11824 & 0.50732 & 0.58393 & 0.47274 & 0.72522 \\
0.00611 & 0.00305 & 0.00781 & 0.17975 & 0.35640 \\
0.11083 & 0.48919 & 0.53129 & 0.29006 & 0.37001 \\
0.87767 & 0.29839 & 0.07175 & 0.00853 & 0.00344 \\
0.34786 & 0.36358 & 0.11855 & 0.03340 & 0.02159
\end{array}\right]
$$

The weighted decision matrix was calculated. The obtained ideal and negative ideal solutions are given below. 


$V i j=\left[\begin{array}{lllll}0.00127 & 0.02171 & 0.02807 & 0.00442 & 0.00498 \\ 0.04112 & 0.01209 & 0.00395 & 0.08696 & 0.03161 \\ 0.00062 & 0.01582 & 0.00522 & 0.00075 & 0.00048 \\ 0.00033 & 0.01810 & 0.01483 & 0.01243 & 0.01029 \\ 0.04312 & 0.02217 & 0.01028 & 0.10721 & 0.07496 \\ 0.00024 & 0.00023 & 0.00042 & 0.00564 & 0.00486 \\ 0.00000 & 0.00039 & 0.00039 & 0.00002 & 0.00006 \\ 0.00072 & 0.00038 & 0.00049 & 0.00000 & 0.00001 \\ 0.00000 & 0.07802 & 0.06381 & 0.00270 & 0.00579 \\ 0.00058 & 0.00015 & 0.00024 & 0.00004 & 0.00005 \\ 0.01767 & 0.01960 & 0.00819 & 0.01082 & 0.00377 \\ 0.00000 & 0.03713 & 0.02892 & 0.00026 & 0.00034 \\ 0.00345 & 0.07515 & 0.08915 & 0.00397 & 0.00686 \\ 0.02565 & 0.11771 & 0.11588 & 0.08112 & 0.13126 \\ 0.00133 & 0.00071 & 0.00155 & 0.03085 & 0.06450 \\ 0.02404 & 0.11350 & 0.10543 & 0.04978 & 0.06697 \\ 0.19040 & 0.06923 & 0.01424 & 0.00146 & 0.00062 \\ 0.07546 & 0.08436 & 0.02353 & 0.00573 & 0.00391\end{array}\right]$

$$
\begin{aligned}
& V^{+}=(0.19040,0.00015,0.00024,0.10721,0.13126) \\
& V^{-}=(0.00000,0.11771,0.11588,0.00000,0.00001)
\end{aligned}
$$

Table 3. TOPSIS Results and Evaluation Ranks

\begin{tabular}{|c|c|c|c|c|}
\hline & S+ & S- & C & Evaluation rank \\
\hline PW & 0.2520 & 0.1303 & 0.3408 & 14 \\
\hline PB & 0.1811 & 0.1842 & 0.5043 & 3 \\
\hline OSB & 0.2544 & 0.1504 & 0.3716 & 11 \\
\hline HB & 0.2455 & 0.1428 & 0.3678 & 12 \\
\hline MDF/HDF & 0.1595 & 0.1981 & 0.5540 & 1 \\
\hline OFB & 0.2499 & 0.1649 & 0.3975 & 6 \\
\hline MWP & 0.2549 & 0.1646 & 0.3924 & 9 \\
\hline SCWP & 0.2544 & 0.1646 & 0.3928 & 8 \\
\hline CWP & 0.2702 & 0.0658 & 0.1958 & 17 \\
\hline PFFOTW & 0.2544 & 0.1649 & 0.3932 & 7 \\
\hline RP & 0.2363 & 0.1472 & 0.3839 & 10 \\
\hline NP & 0.2589 & 0.1186 & 0.3141 & 15 \\
\hline PWP & 0.2732 & 0.0510 & 0.1573 & 18 \\
\hline OPPB & 0.2346 & 0.1564 & 0.4001 & 5 \\
\hline HSP & 0.2146 & 0.1785 & 0.4542 & 4 \\
\hline WPPP & 0.2429 & 0.0876 & 0.2649 & 16 \\
\hline IRW & 0.1823 & 0.2212 & 0.5483 & 2 \\
\hline SW & 0.2176 & 0.1240 & 0.3630 & 13 \\
\hline
\end{tabular}

The distance of every possible solution from the ideal solution and negative ideal solution was calculated. The relative degree of approximation was obtained. The economic contribution of product types were ranked, as shown in Table 3 , according to the relative degree of approximation. 


\section{RESULTS AND DISCUSSION}

According to the importance levels, the ranking of criteria from high to low were as follows: import quantity, production quantity, import value, export value, and export quantity. This result is quite interesting because contrary to expectations, the export-related criteria, which provide currency inflow, were found to be less important by the relevant analysis. The reasons behind this situation are somewhat complex; therefore, this result needs to be interpreted with caution. The Turkish economy is one of the most important emerging economies in the world (Kocakaplan et al. 2012). Many of the developing countries are faced with current account deficits as a consequence of using a high level of import input in production (Yurdakul and Ucar 2015) and Turkey's exports heavily depend on imported intermediate goods (Karagöz 2016). Economic growth depends on the import to produce export goods. Therefore, growth in the economy brings a production increase, which will inevitably increase imports and eventually lead to an account deficit (Yurdakul and Ucar 2015). In order to overcome the trade deficit, exports should be encouraged (Günçavdı and Suna Kayam 2017). Policies aiming to reduce the dependency of exports on imports are needed (Yurdakul and Ucar 2015). Guiding direct investments to more value-added sectors for increasing export volume might be helpful to solve the chronic trade deficit problem in Turkey (Kayhan et al. 2013).

Based on economic contribution, when the importance levels of the products are evaluated, the ranking was as follows: $\mathrm{MDF} / \mathrm{HDF}$, industrial roundwood, particle board, household and sanitary papers, other paper and paper board, other fiber board, pulp from fibers other than wood, semi-chemical wood pulp, mechanical wood pulp, recovered paper, OSB, hardboard, sawn wood, plywood, newsprint, wrapping, packing paper and paper board, chemical wood pulp, and printing and writing papers.

The production quantity of industrial roundwood is much more than the others, and this situation causes a significant difference in ranking. The paper and paper board product group was the most prominent group in imports, and they were in first place in terms of both import quantity and import value. Although the wood-based panels product group was the most prominent group in export quantity, the paper and paper board group was the most prominent group in export value, while the wood-based panels group was second. All the points mentioned above must be approached with caution in order to interpret the results correctly.

Overall, these results indicate that there are two substantial product groups in Turkey's forest products industry, and these are wood based panels and the paper and paper board product groups. The wood-based panels group is the most prominent group and its power comes from production. Most of the produced industrial roundwood is consumed by this product group in the domestic market. This is the reason behind the export quantity and export value of industrial round wood group being very low compared to production quantity.

Generally, Turkey imports the products of the fiber furnish group. According to records of FAO, there is not any mechanical and chemical wood pulp production. The quantity of chemical wood pulp is imported. There is a serious inadequacy here. Due to the findings, the domestic market demands these products. Therefore, it is possible to say that the mentioned products have potential in market.

As noted earlier, the paper and paper board products group was found to be the most prominent one in export value, while the wood-based panels group was second. Despite the export quantity of the paper and paper board products group being less than 
wood-based panels, its contribution to currency inflow is higher. Therefore, it can be said that the added value of these products is greater. As reiterated before, to reduce the trade deficit of Turkey, investing in this group may be beneficial.

\section{CONCLUSIONS}

1. The aim of the present research was to examine forest products according to their economic contribution, help to increase currency inflow, decrease trade deficit, and to indicate whether MCDM methods are appropriate for natural resources and economics related planning. Considering all criteria and alternatives, the ranking of product types is as stated previously. MDF/HDF is the most contributory product of Turkey's forest products industry. Nevertheless, household and sanitary papers and other paper and paper board products were found to be of great economic potential. The findings from this study suggest that new investments should be made in the production of these products.

2. The present work could add a new dimension to forestry research. According to carried out literature review, the existing literature on decision-making applications in forestry has had some limitations. These studies are usually in forestry applications and not covering the forest products industry and economics. The present study aims to fill a gap in the literature. In this respect, the study presented here is one of the pioneering works as far as we know for today. This paper not only makes a theoretical contribution but also a practical contribution. The findings are concrete, and the proposed method could be improved.

3. Several limitations of the study deserve mentioning. The 2018 data are not included. For today, the most up to date year of FAOSTAT is 2017. Despite the fact that FAOSTAT is official, reliable, and comprehensive, in the future different databases may be included. Thus, more criteria could be added, and more detailed findings may be given. More information on criteria and alternatives would help to establish a greater degree of accuracy on analyses. Despite conducted comprehensive research, reliable data is limited in availability. Therefore, the tested aspects are limited too. Having five criteria is an important shortage of present study. Adding more criteria will include more aspects and may make the results more reasonable.

\section{REFERENCES CITED}

Abidin, M., Rusli, R., and Shariff, A. (2016). "Technique for Order Performance by Similarity to Ideal Solution (TOPSIS)-entropy methodology for inherent safety design decision making tool," Procedia Engineering 148, 1043-1050. DOI:10.1016/j.proeng.2016.06.587

Ao, Z., Chunyou, W., and Enxu, W. (2011) "Research on energy consumption evaluation combined with endogenous pollutants of China based on Entropy-TOPSIS," Chinese Journal of Population Resources and Environment 9(), 71-76. DOI: 10.1080/10042857.2011.10685050

Bakhoum, E. S., and Brown, D. C. (2013). "A hybrid approach using AHP-TOPSISentropy methods for sustainable ranking of structural materials," Int. J. Sustain. Eng. 
6, 212-224. DOI: 10.1080/19397038.2012.719553

Bettinger, P., Boston, K., Siry, J. P., and Grebner, D. L. (2017). Forest Management and Planning, $2^{\text {nd }}$ Ed., Academic Press, New York, NY.

Food and Agriculture Organization of the United Nations (FAO) (2018). FAO Yearbook of Forest Products 2016, Food and Agriculture Organization of the United Nations Publisher, Rome.

Food and Agriculture Organization of the United Nations (FAO) (2019). "Forestry production and trade database," (http://www.fao.org/faostat/en/\#data/FO), Accessed 10 February 2019.

General Directorate of Forestry (GDF) (2015). Turkey Forest Assets 2015, The Ministry of Forestry and Water Affairs Publications, Ankara.

Günçavdı, Ö., and Suna Kayam, S. (2017). "Unravelling the structure of Turkish exports: Impediments and policy," J. Policy Model 39, 307-32. DOI:

10.1016/j.jpolmod.2016.09.001

Huang, W., Shuai, B., Sun, Y., Wang, Y., and Antwi, E. (2018). "Using entropy-TOPSIS method to evaluate urban rail transit system operation performance: The China case," Transp. Res. Part A Policy Pract. 111, 292-303. DOI: 10.1016/j.tra.2018.03.025

Hwang, C., and Yoon, K. (1981). Multiple Attribute Decision Making Methods and Applications: A State-of-the-art Survey, Springer-Verlag, Berlin.

İstanbul Chamber of Industry (ISO) (2019). "2018 - İSO 500 | Türkiye'nin 500 Büyük Sanayi Kuruluşu. Iso500.org.tr.," (http://www.iso500.org.tr/top-500-industrialenterprises/2018/), Accessed 17 June 2019.

Karagöz, K. (2016). "Determining factors of Turkey's export performance: An empirical analysis," Procedia Econ. Finance, 38, 446-457. DOI: 10.1016/S22125671(16)30216-7

Kayhan, S., Bayat, T., and Yüzbaşı, B. (2013). "Government expenditures and trade deficits in Turkey: Time domain and frequency domain analyses," Econ. Model. 35, 153-158. DOI: 10.1016/j.econmod.2013.06.022

Kim, A. R. (2016). "A study on competitiveness analysis of ports in Korea and China by entropy weight TOPSIS," Asian J. Shipp. Logist. 32, 187-194. DOI: 10.1016/j.ajsl.2016.12.001

Kocakaplan, Y., Deviren, B., and Keskin, M. (2012). "Hierarchical structures of correlations networks among Turkey's exports and imports by currencies," Phys. A Stat. Mech. its Appl. 391, 6509-6518. DOI: 10.1016/j.physa.2012.07.021

Li, X., Wang, K., Liu, L., Xin, J., Yang, H., and Gao, C. (2011). "Application of the entropy weight and TOPSIS method in safety evaluation of coal mines," Procedia Eng. 26, 2085-2091. DOI: 10.1016/j.proeng.2011.11.2410

Long, Y., Yang, Y., Lei, X., Tian, Y., and Li, Y. (2019). "Integrated assessment method of emergency plan for sudden water pollution accidents based on improved TOPSIS," Shannon Entropy and a Coordinated Development Degree Model 11, 510. DOI: 10.3390/su11020510

Ouyang, L.-Y., Chen, K.-S., Yang, C.-M., and Hsu, C.-H. (2014). "Using a QCACEntropy-TOPSIS approach to measure quality characteristics and rank improvement priorities for all substandard quality characteristics," Int. J. Prod. Res. 52, 3110-3124. DOI: 10.1080/00207543.2013.865092

Tang, H., Shi, Y., and Dong, P. (2019). "Public blockchain evaluation using entropy and TOPSIS,” Expert Syst. Appl., 117, 204-210. DOI: 10.1016/j.eswa.2018.09.048

Tianlin, D., Jianzhong, G., Fang, W., and Renjian, Z. (2019). “Application of entropy- 
based multi-attribute decision-making method to structured selection of settlement," J. Vis. Commun. Image Represent, 58, 220-232. DOI: 10.1016/j.jvcir.2018.11.026

Trade Statistics for International Business Development (TRADE MAP) (2019).

"Trademap.org Database," (https://www.trademap.org/Index.aspx), Accessed 2 May 2019.

Sayareh, J. and Alizmini, H. R. (2014). "A hybrid decision-making model for selecting container seaport in the Persian Gulf," Asian Journal of Shipping \& Logistics 30(1), 75-95. DOI: 10.1016/j.ajsl.2014.04.004

Shannon, C. E. (1948). "A mathematical theory of communication,” Bell System Technical Journal 27, 379-423. DOI: 10.1002/j.1538-7305.1948.tb01338.x

Song, M., Zhu, Q., Peng, J., and Santibanez Gonzalez, E. (2017). "Improving the evaluation of cross efficiencies: A method based on Shannon entropy weight," Computers \& Industrial Engineering 112, 99-106. DOI: 10.1016/j.cie.2017.07.023

Velasquez, M., and Hester, P. (2013). "An analysis of multi-criteria decision making methods," International Journal of Operations Research 10(2), 56-66.

Wang, E., Alp, N., Shi, J., Wang, C., Zhang, X., and Chen, H. (2017). "Multi-criteria building energy performance benchmarking through variable clustering-based compromise TOPSIS with objective entropy weighting," Energy 125, 197-210. DOI: 10.1016/j.energy.2017.02.131

Yang, W., Xu, K., Lian, J., Ma, C., and Bin, L. (2018). "Integrated flood vulnerability assessment approach based on TOPSIS and Shannon entropy methods," Ecological Indicators 89, 269-280. DOI:10.1016/j.ecolind.2018.02.015

Yurdakul, F., and Ucar, B. (2015). "The relationship between current deficit and economic growth: An empirical study on Turkey," Procedia Econ. Finance 26, 101108. DOI: $10.1016 / \mathrm{S} 2212-5671(15) 00885-0$

Zhou, K., Lin, Y., Deng, H., Li, J., and Liu, C. (2016). "Prediction of rock burst classification using cloud model with entropy weight," Trans. Nonferrous Met. Soc. China 26, 1995-2002. DOI: 10.1016/S1003-6326(16)64313-3

Article submitted: September 6, 2019; Peer review completed: November 9, 2019; Revised version received: December 26, 2019; Accepted: December 29, 2019; Published: January 10, 2020.

DOI: 10.15376/biores.15.1.1419-1429 